\title{
Bumblebees in the city: abundance, species richness and diversity in two urban habitats
}

\author{
Bengt Gunnarsson $\cdot$ Lisa Marie Federsel
}

Received: 30 July 2014/ Accepted: 12 November 2014/Published online: 16 November 2014

(C) The Author(s) 2014. This article is published with open access at Springerlink.com

\begin{abstract}
Bumblebees are well known for their contribution to the ecosystem service of pollination. In urban areas, green space management beneficial to pollinators can be an important step in sustaining large urban bee populations. The abundance, number of species and diversity of bumblebees (Bombus spp), as well as the abundance of honeybees (Apis mellifera), were studied in 13 urban gardens (including allotments) and 13 ornamental flowerbeds (in parks and green spaces) in the city centre of Gothenburg, Sweden. In total, 12 species of bumblebees were observed. Species richness was significantly higher in gardens than in flowerbeds, but diversity (Berger-Parker and Simpson indices) was higher in flowerbeds than in urban gardens. The abundance in gardens was significantly higher and approximately twice that found in flowerbeds. The number of honeybee individuals was positively correlated with the abundance of bumblebees. Neither species richness nor abundance of bumblebees was affected by site size. However, a high flowering frequency positively affected the total number of bumblebee and honeybee individuals at the sites. We conclude that urban gardens contribute to sustaining a high abundance of bumblebees in the city centre, and indirectly facilitates small scale urban food production. A pollinator-friendly management of urban green space with plentiful flowering may promote a community of bumblebees with high abundance and diversity.
\end{abstract}

Keywords Apis $\cdot$ Bombus $\cdot$ Ecosystem service . Flowerbeds · Urban biodiversity · Urban gardens

B. Gunnarsson $(\bowtie) \cdot$ L. M. Federsel

Department of Biological and Environmental Sciences, University of Gothenburg, Box 461, 40530 Göteborg, Sweden e-mail: bengt.gunnarsson@bioenv.gu.se

\section{Introduction}

Recently, a number of studies of pollinator communities caused considerable concern due to the presentation of their declining numbers both regionally and globally (e.g. Potts et al. 2010; Bommarco et al. 2012; Burkle et al. 2013). The focus on insect pollinators has often been linked to their effect on flowering plants and the productivity of biomass, seeds and fruits. If the trend of declining numbers of pollinators in the agricultural landscape continues there is a serious risk for lower efficiency in plant production systems. Recent data suggests that the importance of insect pollination on, e.g., crop quality may have been seriously underestimated (Klatt et al. 2014). The long-term consequences of insect pollinators' decline may be catastrophic for human food production.

A focus on sustainability and safe food production, in combination with rapid urbanization, has increased the interest in urban gardening and food production. Urban gardening in major cities in the EU and USA can be seen in light of increasing awareness of global environmental threats and trends of sustainable living (e.g. Lawson 2005). In terms of ecosystem service, the success and usefulness of pollinators as suppliers of a "service" may depend on social-ecological dynamics (Andersson et al. 2007). This suggests that the "value" of pollination is dependent on human actions, e.g. management regimes in urban areas. Here, we focus on the diversity and abundance of bumblebees in relation to two common, but strictly man-made, urban habitats; urban gardens and flowerbeds.

Various insect pollinators, such as bumblebees, contribute to the success of urban gardening in the very centres of cities (e.g. Matteson and Langellotto 2009). Several studies have shown that bumblebees can colonize urban areas with a relatively small cover of green space (e.g. 
Tommasi et al. 2004; Matteson et al. 2008; Hernandez et al. 2009; Matteson and Langellotto 2010). This makes bumblebees especially valuable as providers of ecosystem services in an urban context. Outside city centres, areas such as allotment gardens are florally rich and heterogeneous habitats able to support large and highly diversified populations of bumblebees (e.g. Andersson et al. 2007; Ahrné et al. 2009).

We explored the hypothesis that two specific types of urban habitats, namely urban gardens and flowerbeds, harbour different number of individuals and species of bumblebees. We also examined whether the size of an urban site and abundance of honeybees had an impact on the abundance of bumblebees. The study was conducted in Gothenburg, the second largest city in Sweden.

\section{Materials and methods}

We sampled bumblebees and honeybees at 26 sites in the city of Gothenburg (ca 500,000 inhabitants) in southwestern Sweden. The study included 13 sites with urban gardens (GA) and another 13 sites with traditional flowerbeds (FB), i.e. ornamental floral patches in green spaces in, or close to, the city centre (Table 1). The GA sites included various kinds of allotments, with and without small cottages, but also community gardens and sites with small, built-up growing beds. The FB sites included beds with flowers for ornamental purposes in many kinds of green space such as shopping malls, churchyards, city parks, pocket parks, botanical garden, etc. Residential and/ or commercial areas surrounded all sites. The area of sites varied greatly. In GA sites, the range was $250-45,000 \mathrm{~m}^{2}$ $\left(\right.$ mean $\left.\pm \mathrm{SE} 9,465 \pm 3,336 \mathrm{~m}^{2}\right)$ and in FB sites, $100-60,000 \mathrm{~m}^{2} \quad\left(\right.$ mean $\left.\pm \mathrm{SE} \quad 8,076 \pm 5,287 \mathrm{~m}^{2}\right)$. For smaller sites, almost all of the ground was covered with gardens or flowerbeds, respectively. But for the larger sites, there was some habitat heterogeneity including e.g. lawns and ground covered with shrubs and trees. At each site, we sampled bees in spots with flowering plants. However, flowering differed between sites and we used an index of 1 (low abundance), 2 (medium abundance), or 3 (high abundance) to assess the relative frequency of flowering plants (Table 1). The index was based on a visual assessment at each site. The following percentages of the total sampling area (see below) covered by flowering plants were used: an index of 1 corresponded to $20-35 \%$, an index of $240-55 \%$, and an index of $360-80 \%$. All assessments were made by one of the authors (LMF). Previous studies have shown that visual estimation of vegetation cover is an acceptable sampling method although the percentage is often slightly underestimated (e.g. Gallegos Torell and Glimskär 2009).
Table 1 Study sites in Gothenburg

\begin{tabular}{|c|c|c|c|}
\hline No. & Name of site & Size (ha) & $\begin{array}{l}\text { Index } \\
\text { of flowering }\end{array}$ \\
\hline \multicolumn{4}{|c|}{ Urban gardens } \\
\hline 1 & Gnisterängens odlarförening & 0.9 & 2 \\
\hline 2 & Grön kultur Högsbo & 0.5 & 3 \\
\hline 3 & Kristinedals odlarförening & 1.25 & 3 \\
\hline 4 & Lilla Änggårdskolonin & 0.3 & 3 \\
\hline 5 & Silverkällan & 0.15 & 3 \\
\hline 6 & Skansberget & 0.03 & 1 \\
\hline 7 & Slottskogskolonien & 4.5 & 3 \\
\hline 8 & Solrosparken & 0.025 & 1 \\
\hline 9 & Torpa koloniområde & 0.5 & 2 \\
\hline 10 & Turebergs odlarförening & 0.05 & 2 \\
\hline 11 & Änggårdens koloniförening & 1.7 & 2 \\
\hline 12 & Änggårdens odlarförening & 1.2 & 1 \\
\hline 13 & Örgryte koloniträdgårdar & 1.2 & 3 \\
\hline \multicolumn{4}{|c|}{ Flower beds } \\
\hline 14 & Axel Dahlströms torg & 0.01 & 2 \\
\hline 15 & Berzeliigatan busshållplats & 0.04 & 1 \\
\hline 16 & Bältesspännarparken & 0.025 & 3 \\
\hline 17 & Botaniska trädgården & 4 & 3 \\
\hline 18 & Domkyrkan & 0.3 & 3 \\
\hline 19 & Drottningtorget & 0.01 & 1 \\
\hline 20 & Ekedal busshållplats & 0.01 & 2 \\
\hline 21 & Götaplatsen & 0.03 & 2 \\
\hline 22 & Liseberg södra ingången & 0.01 & 3 \\
\hline 23 & Skäpplandagatans parkering & 0.035 & 2 \\
\hline 24 & Torpagatan & 0.01 & 2 \\
\hline 25 & Trädgårdsföreningen & 6 & 3 \\
\hline 26 & Västergatan & 0.02 & 3 \\
\hline
\end{tabular}

An index of the relative frequency of flowering plants was used: $1=$ low abundance, $2=$ medium abundance, $3=$ high abundance

The sampling was performed on six occasions in July 2013, i.e. day $1,8,12,17,22$ and 29 , between 0900 and $1800 \mathrm{~h}$. All sampling took place on days with a minimum temperature of $17{ }^{\circ} \mathrm{C}$, low wind and no rain. The visiting sequence of the sites varied between sampling dates, so that each site was visited at different times during the day over the sampling period.

At each site, we counted bumblebees and honeybees while walking slowly along a transect at a pre-determined pace and following existing tracks enabling an overview of the site. The sampling area covered $2.5 \mathrm{~m}$ on both sides of the transect. Transect lengths varied slightly with a mean of $85 \mathrm{~m}$ for GA sites and $88 \mathrm{~m}$ for FB sites. In the statistical analysis, all sampling estimates were converted to number of species, or individuals, per $100 \mathrm{~m}$ (i.e. $500 \mathrm{~m}^{2}$ ).

The bumblebees were determined by species in the field, i.e. no bees were killed in our study. We used primarily 
keys specifically developed for field identification of Swedish bumblebees (Söderström 2013). In case of uncertainty, the individual was captured in a transparent plastic vial and examined in detail before it was released again. In a few cases, a photo of the individual was also taken and an expert on bumblebee species identification was consulted. Usually the species identification was unambiguous but in the case of Bombus lucorum there are two rare "sibling species" in Sweden, i.e. B. cryptarum and B. magnus, which could not be distinguished in the field. Thus all individuals were counted as the common species B. lucorum. Inevitably, a few individuals escaped the collecting attempts or were observed too shortly to be identified with certainty. In total, 77 individuals $(7.0 \%)$ of the observed bumblebees were unidentified. Those bumblebees were included in an analysis of the number of individuals but not of species richness. The dominance index of Berger-Parker and the Simpson index were calculated as diversity measures, as recommended by Magurran (2004).

The statistical analysis was performed by two repeated measures ANOVA with covariables. The dependent variables were "species richness" (number of species/100 m) and "number of individuals" (number of individuals/ $100 \mathrm{~m}$ ) of bumblebees at six sampling occasions (withinsubject factor), respectively. The between-subjects factor was "type of site" (urban garden/flower bed) and covariates were "size of site" (ha) and "Apis" (mean number of honeybees per site). For species richness the ANOVA model was: "species richness at Time 1, Time 2, Time 3, Time 4, Time 5, Time 6" (response variable), "type of site" (factor) and "size of site" (covariate). The number of individuals were analysed using the following model: "number of individuals at Time 1, Time 2, Time 3, Time 4, Time 5, Time 6" (response variable), "type of site" (factor) and "size of site" plus "Apis" (covariates). We performed no rarefactions on the number of species on sample size because the design was a repeated measures ANOVA, which means that the samples were not strictly independent. We used the non-parametric Kruskal-Wallis test to examine the relationship between the index of flowering plants and total number of bumblebees and honeybees at each site. The software SPSS v. 19 was used for statistical computations.

\section{Results}

In total, 1,105 individuals of 12 species of bumblebees (Table 2) and 959 individuals of honeybees were observed. The present study employed a repeated measures design, implying that some individuals may have been sampled repeatedly during the investigation period. In addition, wild bee species other than Bombus were observed but excluded
Table 2 Species composition of bumblebees (Bombus spp) observed at urban gardens (GA) and flowerbeds (FB) in Gothenburg, Sweden

\begin{tabular}{lcll}
\hline Species & GA sites (\%) & FB sites (\%) & $\begin{array}{l}\text { Tongue } \\
\text { length }\end{array}$ \\
\hline B. terrestris & 59.4 & 49.1 & $\mathrm{~S}$ \\
B. lapidarius & 19.1 & 23.1 & $\mathrm{~S}$ \\
B. lucorum (spp group) & 8.3 & 11.1 & $\mathrm{~S}$ \\
B. pascuorum & 4.8 & 7.2 & $\mathrm{~L}$ \\
B. hypnorum & 4.5 & 5.3 & $\mathrm{~S}$ \\
B. hortorum & 2.3 & 2.9 & $\mathrm{~L}$ \\
B. pratorum & 0.8 & 1.1 & $\mathrm{~S}$ \\
B. soroëensis & 0.3 & 0 & $\mathrm{~S}$ \\
B. rupestris & 0.3 & 0 & - \\
B. bohemicus & 0 & 0.3 & - \\
B. campestris & 0.2 & 0 & - \\
B. sylvarum & 0.2 & 0 & $\mathrm{~L}$ \\
\hline Percentages are given & & 0 &
\end{tabular}

Percentages are given for individuals identified to species at GA sites $(\mathrm{N}=650)$ and $\mathrm{FB}$ sites $(\mathrm{N}=377)$, respectively. Tongue lengths were long (L) and short (S) tongue, respectively (Ahrné et al. 2009). In cuckoo bumblebees tongue length was not recorded

from the analysis because only a few individuals were recorded.

In GA sites, we observed a total of 11 species of bumblebees, with Bombus terrestris predominating (59.4\%, Table 2). The second most frequently observed species was B. lapidarius $(19.1 \%)$. The number of species per site ranged between three and nine. The total number of individuals per site observed over the sampling period was between 14 and 205 bumblebees, with an average of 54.2 individuals.

In FB sites, eight species of bumblebees were recorded. B. terrestris $(49.1 \%)$ and B. lapidarius $(23.1 \%)$ were the most common species (Table 2) in similarity to GA sites. The observed number of species per site varied between two and seven bumblebees. The number of bumblebee individuals per site was on average 30.8, and ranged between 8 and 70 individuals.

In both types of sites, $B$. terrestris was the predominating species. However, the degree of dominance differed. According to the Berger-Parker index (1/d) FB sites had a higher diversity (2.04) than was observed at the GA sites (1.68). Diversity estimated with the Simpson index (1/D) showed, once again, that FB sites had higher diversity (3.17) than GA sites (2.49). These estimates were based on the individuals observed at repeated measurements for each site.

Following the example of Ahrné et al. (2009), we split the different species into two categories according to tongue length, that is, bees with long and bees with short tongues. The frequency of bumblebees with long tongues 


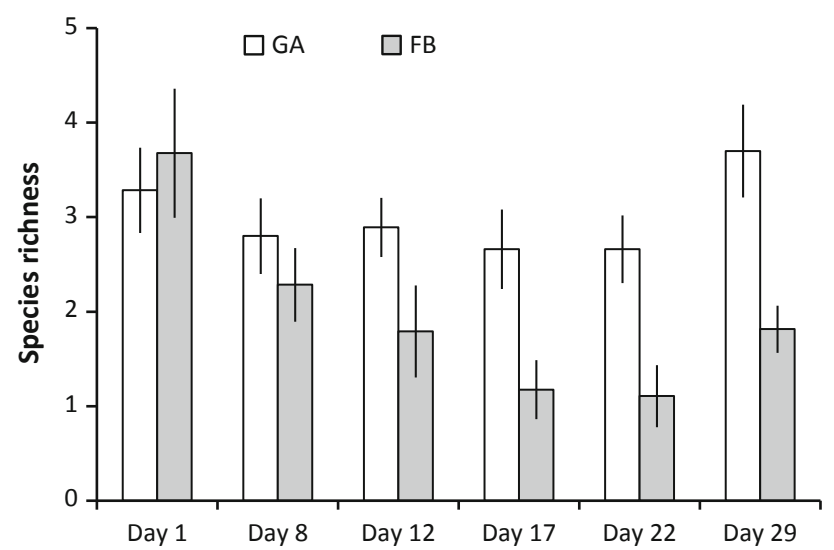

Fig. 1 Species richness (mean $\pm \mathrm{SE}$, no. species/100 m) of bumblebees (Bombus spp) in urban gardens $(\mathrm{GA}, \mathrm{N}=13)$ and flowerbeds $(\mathrm{FB}, \mathrm{N}=13)$ in the city centre of Gothenburg, SW Sweden. Sites were visited six times during July 2013

in GA and FB sites were 7.3 and $10.1 \%$, respectively. These percentages were based on the total number of individuals and identified by species. In addition, three species of cuckoo bumblebees were found in very low frequencies (Table 2) but were not sorted into any category of tongue length.

The mean number of honeybees per site, based on the six sampling occasions, varied between 0.3 and 17.7 individuals (grand mean 6.7) at GA sites, and at FB sites the mean number of honey bees per site was between 0.2 and 33.5 individuals (grand mean 7.9).

Species richness of bumblebees was sampled on six occasions in July (Fig. 1) and the abundances of bumblebees and honeybees were registered simultaneously (Fig. 2). We examined the importance of site type (urban garden GA vs flower bed FB) and two covariates, size of site and number of Apis individuals (the latter only in the analysis of bumblebee abundance), on the response variables species richness (number of species/100 m) and individuals (abundance/100 m) of bumblebees using two separate repeated measures ANOVAs.

In the analysis of the number of species, the betweensubjects factor "type of site" (GA/FB) was significant $(p=0.005)$ but the covariate "size of site" did not contribute significantly to explaining the variance (Table 3). On average, there were 3.0 (SE 0.21) species at GA sites versus 2.0 (SE 0.21) species at FB sites. The within-subject factor, i.e. sampling occasion, varied significantly ( $p=0.021)$ over time. This means that the number of species differed between the sampling dates.

The number of Bombus individuals were significantly influenced by "type of site" $(p=0.032)$ and by one of the covariates "Apis" $(p=0.007)$, i.e. the mean number of honeybee individuals, but not by the "size of site" (Table 3). There were, on average, 10.6 (SE 1.5) Bombus

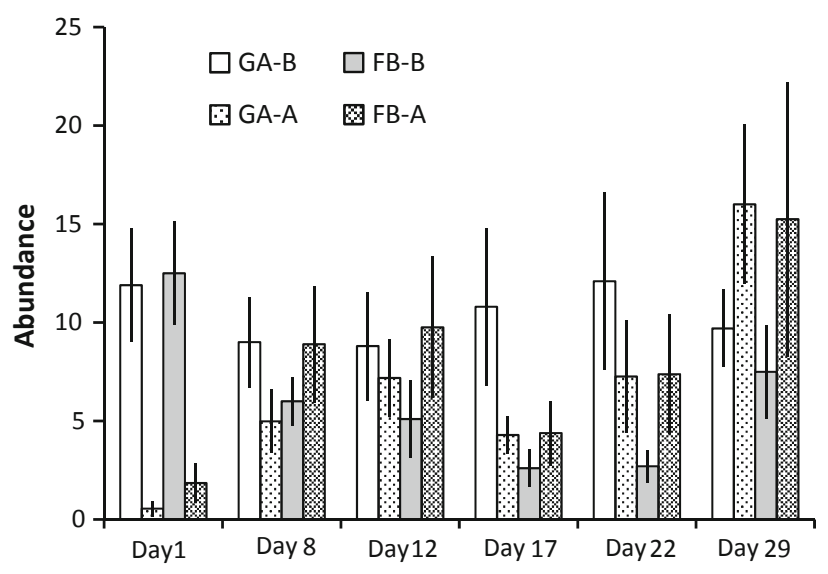

Fig. 2 Abundance (mean \pm SE, no. individuals $/ 100 \mathrm{~m}$ ) of bumblebees (Bombus spp, GA-B) and honeybees (Apis mellifera, GA-A) in urban gardens $(\mathrm{N}=13)$ and flowerbeds $(\mathrm{N}=13$, bumblebees FB-B, honeybees FB-A) in the city centre of Gothenburg, SW Sweden. Sites were visited six times during July 2013

Table 3 Repeated measures ANOVA, with covariates, of species richness and number of individuals of Bombus spp in Gothenburg, Sweden

\begin{tabular}{lrrrl}
\hline Source & df & \multicolumn{1}{l}{ MS } & F & $p$ \\
\hline Species richness & & & & \\
$\quad$ Sampling occasion & 1 & 56.703 & 6.147 & 0.021 \\
Type of site & 1 & 39.469 & 9.910 & 0.005 \\
Size of site & 1 & 5.698 & 1.431 & 0.244 \\
Error & 23 & 3.983 & & \\
Number of individuals & & & & \\
$\quad$ Sampling occasion & 1 & 266.014 & 0.884 & 0.357 \\
Type of site & 1 & 889.337 & 5.234 & 0.032 \\
Size of site & 1 & 61.796 & 0.364 & 0.553 \\
Apis & 1 & $1,533.279$ & 9.024 & 0.007 \\
Error & 22 & 169.914 & & \\
\hline
\end{tabular}

The within-subject factor: "sampling occasion" (day 1, 8, 12, 17, 22, 29). The between-subjects factor: "type of site" (urban garden or flowerbed) and covariates: "size of site" and "Apis" (mean number of honeybees/site)

individuals at GA sites but only 5.8 (SE 1.5) individuals at FB sites. The number of Bombus and Apis individuals were positively correlated for both GA and FB sites (indicated by correlation coefficients). However, the sampling time (within-subject factor) did not contribute to explaining the variance.

We examined whether the total number of individuals of Bombus and Apis observed at each site during our study was related to the index describing the relative frequency of flowering plants. In this test, the GA and FB sites were pooled. The total number of bee individuals differed significantly between the three categories of flowering 
Table 4 Total number of Bombus and Apis individuals along transect at each site (urban gardens and flowerbeds pooled, $\mathrm{N}=26$ ) in relation to a relative index of flowering plants $(1=$ low, $2=$ medium, 3 = high)

\begin{tabular}{llll}
\hline & $\begin{array}{l}\text { Low flowering } \\
\mathrm{N}=5\end{array}$ & $\begin{array}{l}\text { Medium flowering } \\
\mathrm{N}=9\end{array}$ & $\begin{array}{l}\text { High flowering } \\
\mathrm{N}=12\end{array}$ \\
\hline Median & 19 & 61 & 90.5 \\
Mean $\pm \mathrm{SE}$ & $28.5 \pm 8.1$ & $61.8 \pm 10.9$ & $113.8 \pm 25.7$ \\
\hline
\end{tabular}

(Table 4; Kruskal-Wallis test, Chi square $=7.648$, $\mathrm{df}=2, p=0.022$ ). Data suggested that there were more individuals observed at sites with a high relative frequency of flowering plants.

\section{Discussion}

Data for Gothenburg suggested that both species richness and number of bumblebees were higher in urban gardens than in flowerbeds. However, the higher number of species in urban gardens and allotments may be partly misleading in terms of diversity because the Berger-Parker and Simpson indices suggested a more diverse fauna in flower beds. The higher number of species in urban gardens can be due to a sampling effect related to numbers, i.e. the more specimens collected indicates more species observed. A rarefaction analysis was precluded by the repeated-measures design, i.e. the samples at each site were not strictly independent and the same individuals can have been sampled repeatedly. Worker bumblebees in cities seem to be site-specific foragers. In a mark-recapture study in New York City, Matteson and Langellotto (2009) found that recapture rates varied between 30 and $68 \%$ in individual gardens, indicating that bees were revisiting the sites to a great extent. This, of course, means that the diversity indices could also be slightly biased but assuming that the effect was similar it would still be possible to compare the two types of sites.

The high abundance of bumblebees in urban gardens may be of great importance to the urban bee community. This suggests that urban gardens and allotments in Gothenburg may provide bees with valuable food resources, and therefore harbour relatively large populations. Previous studies suggest that gardens are important for attracting and maintaining populations of urban bees (e.g. Goulson et al. 2006; Andersson et al. 2007; Fetridge et al. 2008; Pawelek et al. 2009). The informal management of many gardens and allotments has been suggested as a key in providing bees with suitable habitats (Andersson et al. 2007). Certain habitat qualities in urban gardens of Gothenburg appear to make it possible to house many individuals at numerous sites. For instance, the extended flowering period and high diversity of plants in urban gardens can facilitate maintaining large bumblebee populations in city environments. On the other hand, flowerbeds during our investigation period seemed to attract a more diverse bumblebee community. This may be a coincidence, but it may also be a consequence of the management of flowerbeds. Many species of bees can utilize resources provided by exotic plants (e.g. Frankie et al. 2005), but not all types of plants (e.g. Comba et al. 1999; Corbet et al. 2001), and floral abundance can be a major factor affecting bees in urban environments (Matteson and Langellotto 2010). In a study of bees in urban habitats in Vancouver, British Columbia, Tommasi et al. (2004) found that species richness of bees, including bumblebees, did not differ significantly between city gardens and traditional flowerbeds. Bee abundance was more than three times higher in gardens than flowerbeds in Vancouver. However, Tommasi et al. (2004) did include both botanical and community gardens in their "gardens" category, thus data is not strictly comparable to ours. We included both community gardens and allotments in our "gardens" category, i.e. areas intended for smallscale production of vegetables and flowers, but no parts of botanical gardens. Our data suggested that flowerbeds that are managed in a pollinator-friendly manner could contribute to maintaining a diverse urban bee community.

The species composition of bumblebees in our study sites was similar to that found in previous studies in the southern part of Sweden. In two investigations of bumblebees in urban or periurban sites in Stockholm, Swedeńs largest city, species largely overlapped with the species composition at our sites. Andersson et al. (2007) observed a total of 14 species, with 11 of these found in our samples. In the work of Ahrné et al. (2009), 13 species were reported at study sites along an urban to periurban gradient, and again 11 species overlapped with our data. Moreover, the most common species was $B$. terrestris in the study of Ahrné et al. (2009), as well as in our study sites. In a study of greenways and sown wildflower strips in periurban sites in the southernmost province of Sweden, Haaland and Gyllin (2010) found eight species of bumblebees, of which six were recorded in our samples. However, Haaland and Gyllin (2010) combined two species (B. terrestris and B. lucorum) in their samples, implying an overlap in seven out of nine species. Data from these three studies, together with our findings, suggest that species composition of bumblebee communities in urban and periurban habitats in southern Sweden are fairly predictable.

In previous studies of bee populations, there has been evidence presented for competition between bumblebees and honeybees (e.g. Schaffer et al. 1983; Thomson 2004; Goulson and Sparrow 2009; Hudewenz and Klein 2013). We found a positive co-variation between numbers of 
honeybees and bumblebees in urban gardens and flowerbeds at our study sites. This suggests that resources at our study sites were sufficient, and caused no serious competition between bumblebees and honeybees. It is still possible that individual bees competed for access to single, highly productive flowering plants, but such competition was not strong enough to negatively influence the abundance of bumblebees.

We found no evidence of any effect of size of site on either species richness or abundance. A possible reason for the absence of a correlation between response variables (species richness and abundance of bumblebees) and size could be the great variability in habitat within some of the sites. The flowerbeds we investigated were mostly small areas, ca $100-300 \mathrm{~m}^{2}$ of size. But some of the study sites contained heterogeneous environments with several types of habitats. For instance, in the case of the Gothenburg botanical garden (ca $4 \mathrm{ha}$ ) the ground was partly covered by flower beds, but there were also some shrubs and woodland, lawns and grassland without intensive management, so that the site could be described as a mosaic of different habitat patches. The garden category in our study included many kinds of gardens, i.e. mainly large areas (ca 0.3-4.5 ha) where plants have been grown for about 100 years but also some small $\left(250-500 \mathrm{~m}^{2}\right)$ and newly established community gardens. Thus, the great heterogeneity of vegetation, within and between study sites might explain why no size effect was detected.

One factor that could affect the number of visiting bees is the kind of plants grown at each site. At one of the small gardens (Silverkällan 0.15 ha) we recorded the highest abundance of bumblebees during the course of our study. A possible explanation for the observation at that site could be the extensive growth of Phacelia tanacetifolia, a highly popular plant genus for foraging bumblebees (WaltherHellwig and Frankl 2000). Our data for the total number of individuals per site, including both bumblebees and honeybees, in relation to a relative index of flowering plants provides some credibility to the idea that abundant flowering attract considerable numbers of foraging bee individuals. This suggests that plentiful flowering might have been a major determinant of the abundance of bees recorded at our study sites. However, it should be recalled that single individuals were probably counted more than once, due to the repeated-measures design. Previous studies in agricultural landscapes suggest that mass flowering crops have a strong positive influence on bumblebee densities (e.g. WaltherHellwig and Frankl 2000; Westphal et al. 2003).

Habitats suitable for nesting is another major factor for maintaining bee populations. In an extensive survey of nesting habits of bumblebees in urban environments, Lye et al. (2012) found that the preferred nesting sites were often associated with human activities. This suggests that certain urban habitats could be valuable in providing bumblebees with suitable nest sites (Lye et al. 2012).

Pollination as an ecosystem service in urban areas may be dependent on the management of green space. In order to enhance the efficiency of pollination in urban gardens, it is essential to design green space in a way that attracts insect pollinators. High species richness of flowering plants and an extended growing period may well be crucial factors. Urban gardens and flower beds are two kinds of habitats that can promote and possibly enhance populations of bumblebees in city centres. However, it is not necessarily the size of green space that determines species richness of pollinators. In the city of New York, sunlight and floral abundance were identified as major determinants of urban bee diversity (Matteson and Langellotto 2010). The current trend of urban gardening can provide better conditions for bees but the success of small-scale food production is dependent on maintaining sufficient populations of bees, i.e. a mutual dependence that could develop into a win-win situation. The value of informal management might be of special importance to promote bumblebees in cities (Andersson et al. 2007).

In conclusion, the populations of bumblebees in the city centre of Gothenburg was positively influenced by urban gardens that promoted a high abundance of individuals and many species. Traditional flowerbeds had a lower abundance of bumblebees, but on the other hand the biological diversity was higher than in urban gardens. Extended periods of abundant flowering in different types of urban green spaces might be the key to promoting bumblebee populations. Although more studies in other cities are needed to examine the importance of urban gardens and flower beds to bumblebees in general, we suggest that pollinator-friendly management of urban green space should be the norm in urban planning.

Acknowledgments We thank K. Ahrné and anonymous reviewers for valuable comments on the manuscript and B. Söderström for help with the identification of certain bumblebees. The study was supported by the Swedish Research Council for Environment, Agricultural Sciences and Spatial Planning (FORMAS), Mistra Urban Futures and the Swedish Transport Administration, within the project "Valuation of ecosystem services provided by urban greenery".

Conflict of interest The authors report no conflicts of interest.

Open Access This article is distributed under the terms of the Creative Commons Attribution License which permits any use, distribution, and reproduction in any medium, provided the original author(s) and the source are credited.

\section{References}

Ahrné K, Bengtsson J, Elmqvist T (2009) Bumble bees (Bombus spp) along a gradient of increasing urbanization. PLoS ONE 5:e5574 
Andersson E, Barthel S, Ahrné K (2007) Measuring social-ecological dynamics behind the generation of ecosystem services. Ecol Appl 17:1267-1278

Bommarco R, Lundin O, Smith HG, Rundlöf M (2012) Drastic historic shifts in bumble-bee community composition in Sweden. Proc R Soc B 279:309-315

Burkle LA, Marlin JC, Knight TM (2013) Plant-pollinator interactions over 120 years: loss of species, co-occurrence and function. Science 339:1611-1615

Comba L, Corbet SA, Barron A, Bird A, Collinge S, Miyazaki N, Powell M (1999) Garden flowers: insect visits and the floral reward of horticulturally modified variants. Ann Bot 83:73-86

Corbet SA, Bee J, Dasmahapatra K, Gale S, Gorringe E, La Ferla B, Moorhouse T, Trevail A, Van Bergen Y, Vorontsova M (2001) Native or exotic? Double or single? evaluating plants for pollinator-friendly gardens. Ann Bot 87:219-232

Fetridge ED, Ascher JS, Langellotto GA (2008) The bee fauna of residential gardens in a suburb of New York city (Hymenoptera: apoidea). Ann Entomol Soc Am 101:1067-1077

Frankie GW, Thorp RW, Schindler M, Hernandez J, Ertter B, Rizzardi M (2005) Ecological patterns of bees and their host ornamental flowers in two northern California cities. J Kans Entomol Soc 78:227-246

Gallegos Torell ^̊, Glimskär A (2009) Computer-aided calibration for visual estimation of vegetation cover. J Veg Sci 20:973-983

Goulson D, Sparrow KR (2009) Evidence for competition between honeybees and bumblebees: effects on bumblebee worker size. J Insect Conserv 13:177-181

Goulson D, Hanley ME, Darvill B, Ellis JS (2006) Biotope associations and the decline of bumblebees (Bombus). J Insect Conserv 10:95-103

Haaland C, Gyllin M (2010) Butterflies and bumblebees in greenways and sown wildflower strips in southern Sweden. J Insect Conserv 14:125-132

Hernandez JL, Frankie GW, Thorp RW (2009) Ecology of urban bees: a review of current knowledge and directions for future study. Cities Environ 2:3

Hudewenz A, Klein A-M (2013) Competition between honey bees and wild bees and the role of nesting resources in a nature reserve. J Insect Conserv 17:1275-1283

Klatt BK, Holzschuh A, Westphal C, Clough Y, Smit I, Pawelsik E, Tscharntke T (2014) Bee pollination improves crop quality, shelf life and commercial value. Proc R Soc B 281:20132440
Lawson LJ (2005) City bountiful: a century of community gardening in America. University Calif Press, Berkely \& Los Angeles, p 382

Lye GC, Osborne JL, Park KJ, Goulson D (2012) Using citizen science to monitor Bombus populations in the UK: nesting ecology and the relative abundance in the urban environment. J Insect Conserv 16:697-707

Magurran A (2004) Measuring biological diversity. Blackwell, Oxford

Matteson KC, Langellotto GA (2009) Bumble bee abundance in New York city community gardens: implications for urban agriculture. Cities Environ 2:5

Matteson KC, Langellotto GA (2010) Determinates of inner city butterfly and bee species richness. Urban Ecosyst 13:333-347

Matteson KC, Ascher JS, Langellotto GA (2008) Bee richness and abundance in New York city urban gardens. Ann Entomol Soc Am 101:140-150

Pawelek JC, Frankie GW, Thorp RW, Przybylski M (2009) Modification of a community garden to attract native bee pollinators in urban San Luis Obispo, California. Cities Environ 2:7

Potts SG, Biesmeijer JC, Kremen C, Neuman P, Schweiger O, Kunin WE (2010) Global pollinator decline: trends, impacts and drivers. Trends Ecol Evol 25:345-353

Schaffer WM, Zeh DW, Buchmann SL, Kleihans S, Schaffer MV, Antrim J (1983) Competition for nectar between introduced honey bees and native North American bees and ants. Ecology 64:564-577

Söderström B (2013) Sveriges humlor-en fälthandbok. Entomologiska föreningen, Stockholm (In Swedish)

Thomson D (2004) Competitive interactions between the invasive European honey bee and native bumble bees. Ecology $85: 458-470$

Tommasi D, Miro A, Higo HA, Winston ML (2004) Bee diversity and abundance in an urban setting. Can Entomol 136:851-869

Walther-Hellwig K, Frankl R (2000) Foraging habitats and foraging distances of bumblebees, Bombus spp (Hym., Apidae), in an agricultural landscape. J Appl Entomol 124:299-306

Westphal C, Steffan-Dewenter I, Tscharntke T (2003) Mass flowering crops enhance pollinator densities at a landscape scale. Ecol Lett 6:961-965 